\title{
Clinical characteristics and quality of life of older adults with cognitive impairment in Macao
}

Running title: Cognitive function in older adults

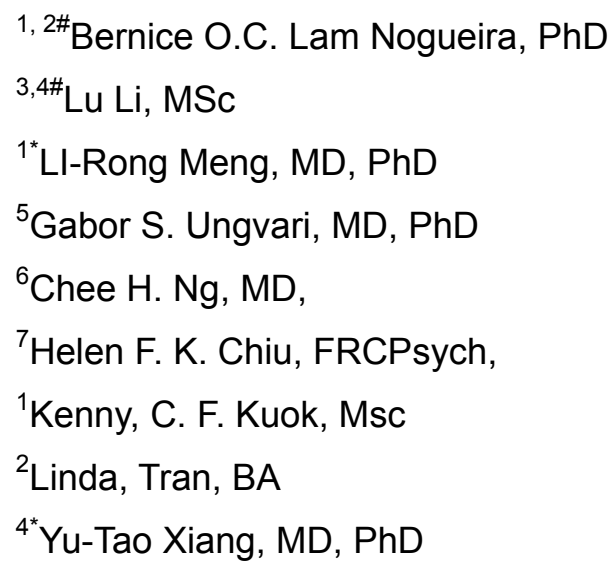

1. School of Health Sciences, Macao Polytechnic Institute Macao SAR, China;

2. Macao Sino-Portuguese Nurses Association, Macao SAR, China;

3. The Affiliated Brain Hospital of Guangzhou Medical University (Guangzhou Huiai Hospital), Guangzhou, China;

4. Unit of Psychiatry, Faculty of Health Sciences, University of Macau, Macao SAR, China;

5. University of Notre Dame Australia / Marian Centre, Perth, Australia;

6. Department of Psychiatry, University of Melbourne, Melbourne, Victoria, Australia;

7. Department of Psychiatry, Chinese University of Hong Kong, Hong Kong SAR, China

\# There authors equally contributed to this work.

*Address correspondence to Dr. Yu-Tao Xiang, 3/F, Building E12, Faculty of Health Sciences, University of Macau, Avenida da Universidade, Taipa, Macau SAR, China. Fax: +853-2288-2314; Phone: +853-8822-4223; E-mail: xyutly@gmail.com; or Dr. Li-Rong Meng, School of Health Sciences, Macao Polytechnic Institute, Macau SAR, China. Phone: +853- 8599-3449; E-mail: Irmeng@ipm.edu.mo

This is the author manuscript accepted for publication and has undergone full peer review but has not been through the copyediting, typesetting, pagination and proofreading process, which may lead to differences between this version and the Version of Record. Please cite this article as doi: 10.1111/psyg.12306

This article is protected by copyright. All rights reserved. 


\section{Abstract}

Background: Little is known about the characteristics of older adults with cognitive impairment in Macao. This study aimed to determine the prevalence of cognitive impairment and quality of life (QOL) of older adults living in the community and nursing homes.

Methods: A consecutive sample of 413 subjects (199 from the community and 214 from nursing homes) was recruited and interviewed using standardized instruments. Cognition was measured with the Repeatable Battery for the Assessment of Neuropsychological Status (RBANS) and QOL with the World Health Organization Quality of Life-BREF.

Result: Altogether 87 subjects (21.0\%) of the sample had cognitive impairment. On multivariate analyses, advanced age ( $p<0.001, \mathrm{OR}=1.06,95 \% \mathrm{CI}: 1.02-1.1)$ and depressive symptoms $(p=0.04, O R=1.07,95 \% \mathrm{CI}: 1.002-1.1)$ were positively associated with cognitive impairment. Married marital status $(p=0.01$, $\mathrm{OR}=0.3,95 \% \mathrm{CI}: 0.1-0.7)$ and higher education level $(\mathrm{P}<0.001, \mathrm{OR}=0.1,95 \%$ CI: 0.06-0.3) were negatively associated with cognitive impairment. After controlling for the confounders, cognitive impairment was significantly associated with lower psychological $\left(F_{(11,412)}=6.3, P=0.01\right)$ and social relationship domains of $\mathrm{QOL}\left(\mathrm{F}_{(11,412)}=4.0, \mathrm{P}=0.04\right)$.

Conclusion: Cognitive impairment was found to be common in community-dwelling and nursing home resident older adults in Macao. Given its negative impact on $\mathrm{QOL}$, appropriate strategies should be implemented to 
improve access to treatment in this population.

Keywords: Cognitive impairment, quality of life, older adults, Macao 


\section{INTRODUCTION}

The world's population aged 60 years and over has exceeded 900 million in 2015 and the figure is expected to increase to two billion by $2050 .{ }^{1}$ Macao has been a Special Administrative Region of China since 1999 after four century of Portugal administration. Latest statistics released by the Macao Government showed that in 2015 the life expectancy was 84.4 years, while the percentage of older adults aged 65 years and above was $8.4 \%$ and this rate is expected to reach $20.7 \%$ by $2036 .^{2}$

There is compelling evidence that cognitive function declines from the age of 50 years and the decline usually accelerates after the age of 65 as part of normal aging process. ${ }^{3}$ Cognitive impairment is a state of impaired cognitive functioning with an intact ability completing basic daily activities referring to the transitional zone between normal aging and dementia. ${ }^{4}$ Cognitive impairment and dementia may share similar pathological changes. ${ }^{5}$ Although not all persons with cognitive impairment convert eventually to dementia, those with cognitive impairment have a greater risk of developing dementia, such as Alzheimer's disease (AD). ${ }^{6}$ It has been proposed that cognitive impairment is a precursor to $A D .^{7}$ Epidemiological studies found that conversion rate from cognitive impairment to dementia ranged between $10 \%$ and $40 \%$ per year. ${ }^{6,8,9}$ Further, it may take at least ten years from the start of dementia pathology before any clinically detectable symptoms appear. ${ }^{10}$ Therefore, early detection of, and intervention in cognitive impairment is essential to delay the conversion to dementia, and hence 
reduce the suffering of the patients and the burden on families and society.

Due to differences in racial, sociocultural, and environmental context and study methodology, large variation in the patterns of cognitive impairment have been found across studies. For example, the prevalence of cognitive impairment ranges between $19.2 \%$ and $38 \%$ in the USA, $2.4 \%-76.6 \%$ in China ${ }^{11-14}$ and was $31.2 \%$ in Arabic countries, and $22.2 \%$ in Taiwan. ${ }^{3,12,15,16}$ The main correlates of cognitive impairment include low education level, cerebrovascular disease, and advanced age. ${ }^{17,18}$ Probably due to lower education and poorer economic conditions, the prevalence of cognitive impairment in developing countries appears higher than that in developed countries. ${ }^{19}$ Therefore, the findings obtained in Western countries could not be applied to the other parts of the world.

The World Health Organization (WHO) defined quality of life (QOL) as the individuals' perception of their position in life in the context of the culture and value systems in which they live and in relation to their goals, expectations, standards and concerns. ${ }^{1} \mathrm{QOL}$ has become an important measure because it reflects the impact of health problems on the individual and also helps professionals to more adequately plan health care. ${ }^{20}$ Persons with cognitive impairment may suffer from a variety of symptoms, such as forgetfulness, lack of attention and poor problem-solving capabilities, all of which may have a detrimental effect on QOL. ${ }^{21,22}$ To the best of our knowledge, there has been no 
study examining the prevalence of cognitive impairment and its association with QOL in older adults in Macao, China.

This study aimed to (1) determine the prevalence of cognitive impairment in older adults aged 50 years and over living in Macao; (2) explore the independent socio-demographic and clinical correlates of cognitive impairment, and (3) examine the association between cognitive impairment and QOL.

\section{METHODS}

\section{Study setting and participants}

This was a cross-sectional study conducted between September 1 and November 30, 2015 in Macao. Macao has one of the highest population density in the world where older adults live in the community or nursing homes. Of the 20 nursing homes in Macao, 11 were randomly selected according to a computer-generated random number table. All the residents in the selected nursing homes were approached and invited to participate in the study. Residents living in the community were consecutively recruited from neighboring social centers in the same districts. The inclusion criteria were (1) age 50 years or older, (2) Chinese ethnicity and fluency in Cantonese or Mandarin, and (3) ability to communicate adequately to complete the interview. Persons with visual impairment and major neurological diseases (e.g. stroke) that would impact on cognitive performance were excluded. The cutoff for age for defining older adults varied from 50 to 65 years across Asian countries and territories according to local cultural and 
professional traditions. In this survey, those aged $>/=50$ years were classified as 'older adults'. The same age cutoff was also used in WHO reports and other studies. ${ }^{23-26}$

\section{Assessment instruments and evaluation}

Participants' socio-demographic and clinical were collected using a standard form designed for this study in a 30-50 minutes interview by one of 36 trained research assistants.

Cognitive functions were measured with the Chinese version of Repeatable Battery for the Assessment of Neuropsychological Status (RBANS). ${ }^{27,28}$ The RBANS is a brief, widely used neuropsychological performance tool that has been validated with good reliability and validity in China. The RBANS covers immediate memory, visuospatial/ constructional abilities, language, attention, and delayed memory. Twelve subtests make up the above five indices: list learning and story recall for the immediate memory index, figure copy and line orientation for the visuospatial/construction index, picture naming and semantic fluency for the language index, coding and digit span for the attention index, list recall, list recognition, story recall and figure recall for the delayed recall index. In this study, cognitive impairment was defined by a fall in the participant's performance by approximately $1.5 \mathrm{SD}$ or more below age-corrected norms. This approach has been commonly used in clinical studies. ${ }^{7,29,30} \mathrm{QOL}$ was measured with the Chinese version of the World Health Organization Quality of Life-BREF 
(WHOQOL-BREF). ${ }^{31,32}$ The WHOQOL-BREF includes 26 items covering four domains: physical health, psychological health, social relationships and environmental factors. A higher score reflects better QOL. Depressive symptoms in the past week was measured with the Chinese version of the Patient Health Questionnaire (PHQ-9). ${ }^{33-35}$ It has nine items; the score of each item ranges from 0 (not at all) to 3 (nearly every day) with a total score between 0 and 27. A higher score indicates more severe depressive symptoms.

\section{Ethical issues}

The study protocol was approved by the Clinical Research Ethics Committee of the Macau Polytechnic Institute. All participants provided written informed consent.

\section{Statistical analysis}

Data was analyzed using SPSS 20.0 for Windows. The comparison between the non-cognitive impairment and cognitive impairment groups regarding basic demographic and clinical characteristics were performed by independent sample t-test, Mann-Whitney $U$ test, and Chi-square test, as appropriate. QOL were compared between the non-cognitive impairment and cognitive impairment groups with analysis of covariance (ANCOVA) after controlling for the potentially confounding effects of variables that significantly differed between the two groups in the above univariate analyses. Multiple logistic regression analyses 
with the "enter" method were performed to determine the independent relationships between cognitive impairment and the socio-demographic and clinical variables. Cognitive impairment was the dependent variable, while variables that significantly differed between the two groups in the above univariate analyses (age, gender, marital status, living with others, education level, monthly household income and the PHQ-9 total score) were entered as the independent variables. The one-sample Kolmogorov-Smirnov test was used to check the normality of distribution for continuous variables. The level of significance will be set at 0.05 (two-tailed).

\section{RESULTS}

Altogether 470 older adults were invited to participate in the study; 413 (199 from the community and 214 from nursing homes) met the study criteria and completed the assessments, thus giving a participation rate of $87.8 \%$.

Table 1 shows the basic demographic and clinical characteristics of the whole sample and by community and nursing home groups. Table 2 presents the comparison between the non-cognitive impairment and cognitive impairment groups regarding demographic and clinical characteristics and QOL. Compared to the non-cognitive impairment group, participants with cognitive impairment were more likely to be older, reside in nursing homes, had less monthly household income, lower education level and more severe depressive symptoms, while they were less likely to be male, married and living with others. After 
controlling for the above significant variables between the two groups, there were significant differences between the two groups in the psychological $\left(F_{(11,412)}\right.$ $=6.3, \mathrm{P}=0.01)$ and social $\left(\mathrm{F}_{(11,412)}=4.0, \mathrm{P}=0.04\right)$, but not in physical $\left(\mathrm{F}_{(11,412)}=\right.$ $0.6, \mathrm{P}=0.4)$ and environmental $\mathrm{QOL}$ domains $\left(\mathrm{F}_{(11,412)}=1.5, \mathrm{P}=0.2\right)$.

Table 3 displays the subtest and index scores of RBANS by age groups. Cognitive performance declined with increasing age, especially after 60 years. Table 4 shows the independent correlates of cognitive impairment. Advanced age $(P<0.001, O R=1.06,95 \% C I: 1.03-1.1)$ and severe depressive symptoms $(P=0.03, \quad O R=1.07,95 \% C I: 1.005-1.1)$ were positively associated with cognitive impairment, while married marital status $(P=0.01, O R=0.3,95 \%$ CI\%:0.1-0.7) and higher education level ( $P<0.001, \mathrm{OR}=0.1,95 \% \mathrm{CI}: 0.06-0.3)$ were negatively associated with cognitive impairment.

\section{DISCUSSION}

To the best of our knowledge, this was the first study on cognitive impairment and its association with $\mathrm{QOL}$ in older adults living in Macao. The cognitive impairment rate of $21.0 \%$ is broadly consistent with previous findings in older adults in China $(2.4-76.6 \%) .{ }^{11-13}$ The wide variation in the prevalence of cognitive impairment could be due to differences in diagnostic criteria, rating instruments and sampling methods. For example, some studies established the diagnosis of cognitive impairment with the Mini-Mental State Examination $(M M S E){ }^{12,14,36,37}$ while others used the Clinical Dementia Rating scale (CDR). ${ }^{38}$ In 
addition, different age ranges may also influence the results. For example, in persons aged 90 years and older and persons aged 50 years and older, the prevalence of cognitive impairment was $77.6 \%$ and $2.4 \%$, respectively. ${ }^{12,13}$

Consistent with previous findings, ${ }^{39}$ advanced age was positively associated with cognitive impairment; the prevalence of cognitive impairment was 9.3\%, $5.6 \%, 22.2 \%$ and $44.1 \%$ in $50-59,60-69,70-79$ and 80 years and older groups, respectively. Results of this study are consistent with the finding that after the age of 60 years the prevalence of cognitive impairment increases significantly with age ${ }^{19}$; cognitive function declines from the age of 50 years and accelerates after 65 years of age. ${ }^{3}$ Consistent with earlier findings, ${ }^{40}$ in this study higher education level was negatively associated with cognitive impairment $(P<0.001$, $\mathrm{OR}=0.1,95 \% \mathrm{CI}: 0.06-0.3)$ indicating that higher education may be a protective factor for cognitive impairment.

The association of the severity of depressive symptoms with cognitive impairment found in this study replicates the results of several other studies. ${ }^{41-44}$ Depression is closely associated with certain cognitive components, such as memory, attention and decision making. ${ }^{45} \mathrm{~A}$ longitudinal community-based study found that although depressive symptoms were transiently associated with impaired cognitive performance, they did not necessarily increase the risk of conversion to dementia. ${ }^{46}$ In addition, measures on depression may overlap with items measuring cognitive deterioration. For example, the item "Trouble concentrating on things, such as reading the newspaper or watching television" 
in the PHQ-9 reflect aspects of both mood and cognition. Furthermore, the underlying neuropathological conditions leading to cognitive impairment may also generate depressive symptoms. ${ }^{19}$ Finally, it has been suggested that the relationship between depression and cognitive impairment could be mediated by confounding factors, such as hypothyroidism, ${ }^{47}$ antidepressant use, ${ }^{48}$ chronic distress, $^{49}$ and vascular diseases. ${ }^{44,50,51,53}$ It is likely, however that the association between depressive symptoms and cognitive impairment is bidirectional. Due to the cross-sectional design of this study, the causal relationship between them could not be examined leaving this task to future investigations.

In this study, cognitive impairment significantly reduced the psychological and social relationship domains of QOL. According to the distress/protection QOL model, ${ }^{54} \mathrm{QOL}$ is determined by an interaction between protective (e.g., social support) and distressing factors (e.g., major medical conditions). Owing to the personal suffering related to decline in attention, memory, language and thinking in the context of cognitive impairment, cognitively impaired older adults were expected to have a lower $\mathrm{QOL}^{55}$, which was confirmed by this study.

The results of this study should be interpreted with caution due to several methodological limitations. First, due to the cross-sectional design of the survey, the causality between cognitive impairment and other variables could not be explored. Second, other sources of information associated with cognitive impairment, such as activities of daily and neuro-imagining tests on vascular 
diseases were not available. Third, a fall in the subject's performance by approximately $1.5 \mathrm{SD}$ or more below age-corrected norms recommended to define cognitive impairment by previous studies, ${ }^{7,29,30}$ was used in this study without testing the psychometric properties of this criterion. Finally, the participation of genders was not equal; the preponderance of women in the study sample reflects the real gender ratio of older adults in Macao.

In conclusion, considering the negative consequences of cognitive impairment, it is critical to address the issue of cognitive decline in older adults in Macao and implement appropriate strategies to improve access to treatment. Longitudinal studies are warranted to investigate the socio-demographic and clinical predictors of cognitive impairment.

\section{ACKNOWLEDGEMENTS}

This study was funded by a grant from Macao Polytechnic Institute, Macao, China (RP/ESS-05/2015). The authors thank colleagues in Caritas Macau, Macao Sino-Portuguese Nurses Association, Seniors Academy of Macao Polytechnic Institute and other organizations involved and all participants in this study. The authors are grateful to research assistants in Nursing School at Macao Polytechnic Institute for their contributions to the data collection and dataset establishment.

\section{CONFLICT OF INTEREST STATEMENT}


The authors declare no conflicts of interest concerning this article.

This article is protected by copyright. All rights reserved. 


\section{REFERENCES}

1. WHO. The World Health Organization Quality of Life assessment (WHOQOL): position paper from the World Health Organization. Social Science \& Medicine 1995; 41: 1403-1409.

2. The Government Information Bureau of the Macao. Macao Yearbook 2015, 2015.

3. Angevaren M, Aufdemkampe G, Verhaar HJ, Aleman A, Vanhees L. Physical activity and enhanced fitness to improve cognitive function in older people without known cognitive impairment. The Cochrane database of Systematic Reviews 2008; Cd005381.

4. Artero S, Petersen R, Touchon J, Ritchie K. Revised criteria for mild cognitive impairment: validation within a longitudinal population study. Dementia and Geriatric Cognitive Disorders 2006; 22: 465-470.

5. Cheng $Y$, Xiao S. Recent research about mild cognitive impairment in China. Shanghai Archives Psychiatry 2014; 26: 4-14.

6. Mitchell AJ, Shiri-Feshki M. Rate of progression of mild cognitive impairment to dementia--meta-analysis of 41 robust inception cohort studies. Acta Psychiatrica Scandinavica 2009; 119: 252-265.

7. Griffith HR, Netson KL, Harrell LE, Zamrini EY, Brockington JC, Marson DC. Amnestic mild cognitive impairment Diagnostic outcomes and clinical prediction 
over a two-year time period. Journal of the International Neuropsychological Society 2006; 12: 166-175.

8. Bruscoli M, Lovestone S. Is MCI really just early dementia? A systematic review of conversion studies. International Psychogeriatrics 2004; 16: 129-140.

9. Geslani DM, Tierney MC, Herrmann N, Szalai JP. Mild cognitive impairment: an operational definition and its conversion rate to Alzheimer's disease. Dementia and Geriatric Cognitive Disorders 2005; 19: 383-389.

10. Feng L, Chiu H, Chong M-Y, Yu X, Kua E-H. Dementia in Chinese populations: Current data and future research. Asia-Pacific Psychiatry 2011; 3: 109-114.

11. Zhuang JP, Wang G, Cheng Q, et al. Cognitive impairment and the associated risk factors among the elderly in the Shanghai urban area: a pilot study from China. Translational Neurodegeneration 2012; 1: 22.

12. Wang $Z$, Dong $B$, Zeng $G$, et al. Is there an association between mild cognitive impairment and dietary pattern in Chinese elderly? Results from a cross-sectional population study. BMC Public Health 2010; 10: 595.

13. Yao YH, Xu RF, Tang HD, et al. Cognitive impairment and associated factors among the elderly in the Shanghai suburb: findings from a low-education population. Neuroepidemiology 2010; 34: 245-252.

14. Qiu CJ, Tang MN, Zhang W, et al. The prevalence of mild cognitive impairment among residents aged 55 or over in Chengdu area (in Chinese). Zhonghua liu xing bing xue za zhi = Zhonghua liuxingbingxue zazhi 2003; 24: 1104-1107. 
15. Afgin $A E$, Massarwa $M$, Schechtman $E$, et al. High prevalence of mild cognitive impairment and Alzheimer's disease in arabic villages in northern Israel: impact of gender and education. Journal of Alzheimer's Disease 2012; 29: 431-439.

16. Wu MS, Lan TH, Chen CM, Chiu HC, Lan TY. Sociodemographic and health-related factors associated with cognitive impairment in the elderly in Taiwan. BMC Public Health 2011; 11: 1-8.

17. Ebly EM, Hogan DB, Parhad IM. Cognitive impairment in the nondemented elderly. Results from the Canadian Study of Health and Aging. Archives of Neurology 1995; 52: 612-619.

18. Panza F, D'Introno A, Colacicco AM, et al. Depressive symptoms, vascular risk factors and mild cognitive impairment. The Italian longitudinal study on aging. Dementia and Geriatric Cognitive Disorders 2008; 25: 336-346.

19. Nie $H, X u Y$, Liu $B$, et al. The prevalence of mild cognitive impairment about elderly population in China: a meta-analysis. International Journal of Geriatric Psychiatry 2011; 26: 558-563.

20. WHO. Development of the World Health Organization WHOQOL-BREF quality of life assessment. The WHOQOL Group. Psychological Medicine 1998; 28: 551-558.

21. Barrios H, Narciso S, Guerreiro M, Maroco J, Logsdon R, de Mendonca A. Quality of life in patients with mild cognitive impairment. Aging \& Mental Health 2013; 17: 287-292. 
22. Hsiao HT, Li SY, Yang YP, Lin LL, Lin SI, Wang JJ. Cognitive Function and Quality of Life in Community-Dwelling Seniors with Mild Cognitive Impairment in Taiwan. Community Mental Health Journal 2016; 52: 493-498.

23. Dassori AM, Copeland LA, Zeber JE, Miller AL. Factors in second-generation antipsychotic switching patterns in a national sample of older veterans with schizophrenia. Psychiatric Services 2011; 62: 47-53.

24. Xiang YT, Buchanan RW, Ungvari GS, et al. Use of clozapine in older Asian patients with schizophrenia between 2001 and 2009. PloS One 2013; 8: e66154. 25. Xiang YT, Li Y, Correll CU, et al. Common use of high doses of antipsychotic medications in older Asian patients with schizophrenia (2001-2009). International Journal of Geriatric Psychiatry 2013.

26. WHO. Information Needs for Research, Policy and Action on Ageing and Older Adults, 2001.

27. Cheng Y, Wu W, Wang J, Feng W, Wu X, Li C. Reliability and validity of the Repeatable Battery for the Assessment of Neuropsychological Status in community-dwelling elderly. Archives of Medical Science 2011; 7: 850-857.

28. Randolph C, Tierney MC, Mohr E, Chase TN. The Repeatable Battery for the Assessment of Neuropsychological Status (RBANS): preliminary clinical validity. Journal of Clinical and Experimental Neuropsychology 1998; 20: 310-319.

29. Farias ST, Mungas D, Reed BR, Harvey D, DeCarli C. Progression of mild cognitive impairment to dementia in clinic- vs community-based cohorts. Archives of Neurology 2009; 66: 1151-1157. 
30. Duff K, Hobson VL, Beglinger LJ, O'Bryant SE. Diagnostic accuracy of the RBANS in mild cognitive impairment: limitations on assessing milder impairments. Archives of Clinical Neuropsychology 2010; 25: 429-441.

31. Fang JQ, Hao YT, Li CX. Reliability and validity for Chinese version of WHO quality of life scale. Chinese Mental Health Journal 1999; 13: 203-205.

32. WHO. Development of the World Health Organization WHOQOL-BREF quality of life assessment. The WHOQOL Group. Psychological Medicine 1998; 28: 551-558.

33. Chen S, Chiu H, Xu B, et al. Reliability and validity of the PHQ-9 for screening late-life depression in Chinese primary care. International Journal of Geriatric Psychiatry 2010; 25: 1127-1133.

34. Kroenke K, Spitzer RL, Williams JB. The PHQ-9: validity of a brief depression severity measure. Journal of General Internal Medicine 2001; 16: 606-613.

35. Kroenke K, Spitzer RL, Williams JB. The Patient Health Questionnaire-2: validity of a two-item depression screener. Medical Care 2003; 41: 1284-1292. 36. Yu ES, Liu WT, Levy $P$, et al. Cognitive impairment among elderly adults in Shanghai, China. Journals of Gerontology: Series A 1989; 44: S97-106.

37. Su X, Shang $L, X u Q$, et al. Prevalence and predictors of mild cognitive impairment in Xi'an: a community-based study among the elders. PloS One 2014; 9: e83217. 
38. Ding $D$, Zhao $Q$, Guo $Q$, et al. Prevalence of mild cognitive impairment in an urban community in China: a cross-sectional analysis of the Shanghai Aging Study. Alzheimer's \& Dementia 2015; 11: 300-309 e302.

39. Duff K, Patton D, Schoenberg MR, Mold J, Scott JG, Adams RL. Age- and education-corrected independent normative data for the RBANS in a community dwelling elderly sample. Clinical Neuropsychologist 2003; 17: 351-366.

40. Green A, Garrick T, Sheedy D, Blake H, Shores A, Harper C. Repeatable Battery for the Assessment of Neuropsychological Status (RBANS): Preliminary Australian normative data. Australian Journal of Psychology 2008; 60: 72-79.

41. Stepaniuk J, Ritchie LJ, Tuokko H. Neuropsychiatric impairments as predictors of mild cognitive impairment, dementia, and Alzheimer's disease. American Journal of Alzheimer's Disease \& Other Dementias 2008; 23: 326-333. 42. Devanand DP, Sano M, Tang MX, et al. Depressed mood and the incidence of Alzheimer's disease in the elderly living in the community. Archives of General Psychiatry 1996; 53: 175-182.

43. Panza F, Frisardi V, Capurso C, et al. Late-life depression, mild cognitive impairment, and dementia: possible continuum? American Journal of Geriatric Psychiatry 2010; 18: 98-116.

44. Barnes DE, Alexopoulos GS, Lopez OL, Williamson JD, Yaffe K. Depressive symptoms, vascular disease, and mild cognitive impairment: findings from the Cardiovascular Health Study. Archives of General Psychiatry 2006; 63: 273-279. 
45. Crespo I, Santos A, Valassi E, Pires P, Webb SM, Resmini E. Impaired decision making and delayed memory are related with anxiety and depressive symptoms in acromegaly. Endocrine 2015; 50: 756-763.

46. Becker JT, Chang YF, Lopez OL, et al. Depressed mood is not a risk factor for incident dementia in a community-based cohort. American Journal of Geriatric Psychiatry 2009; 17: 653-663.

47. Morimoto SS, Kanellopoulos D, Alexopoulos GS. Cognitive Impairment in Depressed Older Adults: Implications for Prognosis and Treatment. Psychiatric Annals 2014; 44: 138-142.

48. Ravaglia G, Forti P, Lucicesare A, et al. Prevalent depressive symptoms as a risk factor for conversion to mild cognitive impairment in an elderly Italian cohort. American Journal of Geriatric Psychiatry 2008; 16: 834-843.

49. Wilson RS, Schneider JA, Boyle PA, Arnold SE, Tang Y, Bennett DA. Chronic distress and incidence of mild cognitive impairment. Neurology 2007; 68: 2085-2092.

50. Thomas AJ, O'Brien JT. Depression and cognition in older adults. Current Opinion in Psychiatry 2008; 21: 8-13.

51. Richard E, Reitz C, Honig LH, et al. Late-life depression, mild cognitive impairment, and dementia. JAMA Neurology 2013; 70: 374-382.

52. Pilotto A, Turrone R, Liepelt-Scarfone I, et al. Vascular Risk Factors and Cognition in Parkinson's Disease. Journal of Alzheimer's Disease 2016; 51: 563-570. 
53. Flicker L. Vascular factors in geriatric psychiatry: time to take a serious look. Current Opinion in Psychiatry 2008; 21: 551-554.

54. Voruganti L, Heslegrave R, Awad AG, Seeman MV. Quality of life measurement in schizophrenia: reconciling the quest for subjectivity with the question of reliability. Psychological Medicine 1998; 28: 165-172.

55. Berg AI, Wallin A, Nordlund A, Johansson B. Living with stable MCI: experiences among 17 individuals evaluated at a memory clinic. Aging \& Mental Health 2013; 17: 293-299. 
Table1. Comparison of basic demographic and clinical characteristics of the sample according to different settings $(n=413)$

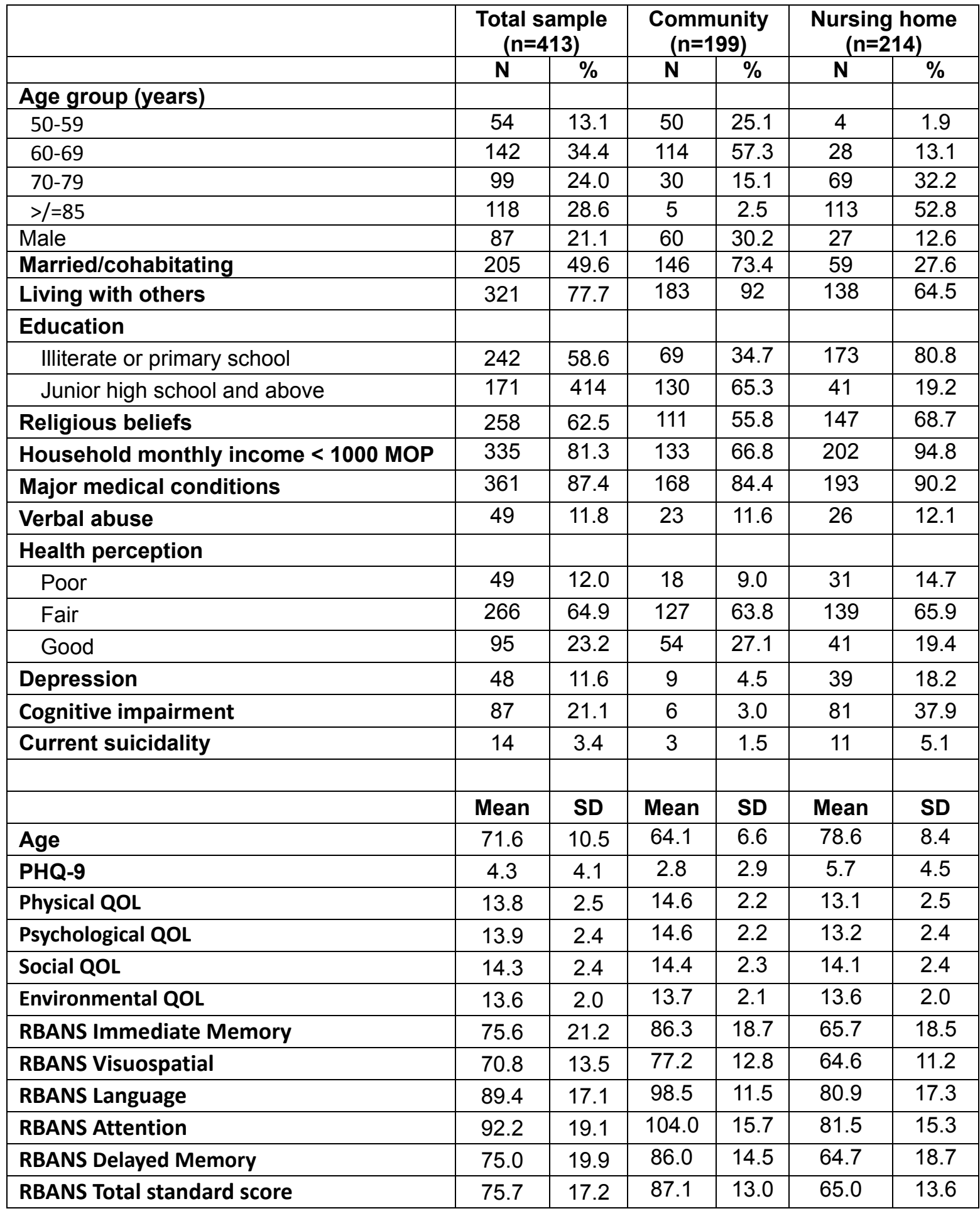

a=Mann-Whitney U test; 1 USD=8.0 MOP; PHQ-9=Patient Health Questionnaire-9; QOL=quality of life, RBANS= Repeatable Battery for the Assessment of Neuropsychological Status

This article is protected by copyright. All rights reserved. 
Table 2. Comparison between those with and without cognitive impairment with respect to basic demographic and clinical characteristics

\begin{tabular}{|c|c|c|c|c|c|c|c|}
\hline & \multicolumn{2}{|c|}{$\begin{array}{c}\text { No cognitive } \\
\text { impairment } \\
(n=326)\end{array}$} & \multicolumn{2}{|c|}{$\begin{array}{c}\text { Cognitive } \\
\text { impairment }(n=87)\end{array}$} & \multicolumn{3}{|c|}{ Statistics } \\
\hline & $\mathbf{n}$ & $\%$ & $\mathbf{N}$ & $\%$ & $x^{2}$ & df & $p$ \\
\hline Place of living & & & & & 75.2 & 1 & $<0.001$ \\
\hline Community & 193 & 59.2 & 6 & 6.9 & & & \\
\hline Nursing house & 133 & 40.8 & 81 & 93.1 & & & \\
\hline Age (years) & & & & & 62.4 & 3 & $<0.001$ \\
\hline $50-59$ & 49 & 15 & 5 & 5.7 & & & \\
\hline $60-69$ & 136 & 41.1 & 8 & 9.2 & & & \\
\hline $70-79$ & 77 & 23.6 & 22 & 25.3 & & & \\
\hline$>/=80$ & 66 & 20.2 & 52 & 59.8 & & & \\
\hline Male & 80 & 24.5 & 7 & 8.0 & 11.2 & 1 & 0.001 \\
\hline Married/cohabitating & 189 & 58.0 & 16 & 18.4 & 43.0 & 1 & $<0.001$ \\
\hline Living with others & 263 & 80.7 & 58 & 66.7 & 7.7 & 1 & 0.005 \\
\hline Education & & & & & 50.5 & 1 & $<0.001$ \\
\hline Illiterate or primary school & 162 & 49.7 & 80 & 92.0 & & & \\
\hline $\begin{array}{l}\text { Junior high school and } \\
\text { above }\end{array}$ & 164 & 50.3 & 7 & 8.0 & & & \\
\hline Religious beliefs & 196 & 60.1 & 62 & 71.3 & 3.6 & 1 & 0.057 \\
\hline $\begin{array}{l}\text { Household } \quad \text { monthly } \\
\text { income }<10000 \text { MOP }\end{array}$ & 252 & 77.3 & 83 & 96.5 & 16.5 & 1 & $<0.001$ \\
\hline Major medical conditions & 295 & 87.4 & 76 & 87.4 & 0.001 & 1 & 0.9 \\
\hline Verbal abuse & 34 & 10.4 & 15 & 17.2 & 3.0 & 1 & 0.08 \\
\hline Health perception & & & & & 0.4 & 2 & 0.7 \\
\hline Poor & 37 & 11.4 & 12 & 14.1 & & & \\
\hline Fair & 212 & 65.2 & 54 & 63.5 & & & \\
\hline Good & 76 & 23.4 & 19 & 22.4 & & & \\
\hline Current suicidality & 9 & 2.8 & 5 & 5.7 & 1.8 & 1 & 0.1 \\
\hline & Mean & SD & Mean & SD & $\mathbf{T} / \mathbf{Z}$ & df & $\mathbf{p}$ \\
\hline Age & 69.3 & 9.5 & 80.0 & 9.7 & -9.2 & 411 & 0.5 \\
\hline PHQ-9 & 3.8 & 3.7 & 6.3 & 4.8 & -8.0 & $--^{a}$ & $<0.001$ \\
\hline Physical QOL & 14.1 & 2.4 & 12.8 & 2.6 & 4.4 & 411 & 0.1 \\
\hline Psychological QOL & 14.2 & 2.3 & 12.7 & 2.5 & 5.3 & 411 & 0.4 \\
\hline Social QOL & 14.4 & 2.3 & 13.5 & 2.6 & 3.0 & 411 & 0.4 \\
\hline Environmental QOL & 13.7 & 2.0 & 13.3 & 2.2 & 1.5 & 411 & 0.4 \\
\hline
\end{tabular}

Bolded values are $p<0.05$; $a=$ Mann-Whitney $U$ test; 1 USD=8.0 MOP; PHQ-9=Patient Health Questionnaire-9;

$\mathrm{QOL}=$ quality of life

This article is protected by copyright. All rights reserved. 
Table 3. Means and standard deviations for RBANS subtests and index scores stratified by age

\begin{tabular}{|c|c|c|c|c|}
\hline & $\begin{array}{c}50-59 \text { years } \\
(n=54) \\
\text { Mean, }(\mathrm{SD})\end{array}$ & $\begin{array}{c}\text { 60-69 years } \\
(n=144) \\
\text { Mean, }(S D)\end{array}$ & $\begin{array}{c}70-79 \text { years } \\
(n=99) \\
\text { Mean, }(S D)\end{array}$ & $\begin{array}{c}>/=80 \text { years } \\
(n=119) \\
\text { Mean, }(\mathrm{SD})\end{array}$ \\
\hline List learning & $\begin{array}{c}23.3(6.9 \\
)\end{array}$ & $22.8(6.5)$ & $18.4(6.7)$ & $12.8(6.8)$ \\
\hline Story memory & $13.8(4.9)$ & $13.5(4.8)$ & $10.9(5.2)$ & $7.8(4.9)$ \\
\hline Figure copy & $10.4(4.7)$ & $9.9(4.5)$ & $8.5(5.1)$ & $6.7(4.9)$ \\
\hline Line orientation & $16.0(3.6)$ & $15.6(3.3)$ & $12.9(4.3)$ & $10.0(4.3)$ \\
\hline Picture naming & $9.7(0.5)$ & $9.5(0.8)$ & $9.1(1.3)$ & $8.1(2.1)$ \\
\hline Semantic fluency & $19.8(5.9)$ & $19.0(5.7)$ & $15.2(5.7)$ & $11.5(4.5)$ \\
\hline Digit span & $13.7(2.4)$ & $13.6(2.2)$ & $11.9(2.9)$ & $10.9(2.8)$ \\
\hline Coding & $34.2(15.1)$ & $32.7(15.2)$ & $19.7(13.2)$ & $9.4(8.8)$ \\
\hline List recall & $4.4(2.7)$ & $4.5(2.8)$ & $3.2(2.8)$ & $1.0(2.0)$ \\
\hline List recognition & $18.3(2.0)$ & $18.4(1.8)$ & $17.0(2.6)$ & $15.1(3.2)$ \\
\hline Story recall & $7.11(2.9)$ & $7.3(2.8)$ & $5.3(3.3)$ & $2.9(2.9)$ \\
\hline Figure recall & $6.3(4.3)$ & $5.3(3.8)$ & $4.6(3.9)$ & $2.3(2.8)$ \\
\hline Immediate Memory & $83.2(19.9)$ & $82.0(20.0)$ & $75.0(19.8)$ & $65.0(19.9)$ \\
\hline Visuospatial & $77.7(15.1)$ & $75.4(12.2)$ & $69.2(13.0)$ & $63.4(10.9)$ \\
\hline Language & $95.4(12.1)$ & $96.3(13.2)$ & $88.0(16.6)$ & $79.4(18.7)$ \\
\hline Attention & $99.7(17.8)$ & $101.0(16.8)$ & $88.3(20.1)$ & $81.6(14.7)$ \\
\hline Delayed Memory & $81.9(17.9)$ & $83.5(16.1)$ & $74.0(19.3)$ & $62.5(18.8)$ \\
\hline Total score & $83.9(15.9)$ & $83.81(14.2)$ & $73.7(16.8)$ & $63.8(14.0)$ \\
\hline
\end{tabular}

This article is protected by copyright. All rights reserved. 
Table 4. Socio-demographic correlates of cognitive impairment (logistic regression analysis)

\begin{tabular}{|l|c|c|c|}
\hline & \multicolumn{3}{|c|}{ Cognitive impairment } \\
\hline & $\mathrm{p}$ & $\mathrm{OR}$ & $95 \% \mathrm{Cl}$ \\
\hline Age (years) & $<\mathbf{0 . 0 0 1}$ & 1.06 & $1.03-1.1$ \\
\hline Male & 0.4 & 0.6 & $0.2-1.7$ \\
\hline Married/cohabitating & $\mathbf{0 . 0 1}$ & 0.3 & $0.1-0.7$ \\
\hline Living with others & 0.1 & 1.7 & $0.8-3.2$ \\
\hline Education & $<\mathbf{0 . 0 0 1}$ & 0.1 & $0.06-0.3$ \\
\hline Household monthly income <10000 MOP & 0.5 & 0.6 & $0.1-2.4$ \\
\hline PHQ-9 & $\mathbf{0 . 0 3}$ & 1.07 & $1.005-1.1$ \\
\hline
\end{tabular}

PHQ-9=Patient Health Questionnaire-9; $Q O L=$ quality of life

This article is protected by copyright. All rights reserved. 


\section{University Library}

\section{- M M N E R VA A gateway to Melbourne's research publications}

Minerva Access is the Institutional Repository of The University of Melbourne

\section{Author/s:}

Lam Nogueira, BOC;Li, L;Meng, L-R;Ungvari, GS;Ng, CH;Chiu, HFK;Kuok, KCF;Tran,

L;Xiang, Y-T

Title:

Clinical characteristics and quality of life of older adults with cognitive impairment in Macao

\section{Date:}

2018-05-01

\section{Citation:}

Lam Nogueira, B. O. C., Li, L., Meng, L. -R., Ungvari, G. S., Ng, C. H., Chiu, H. F. K., Kuok, K. C. F., Tran, L. \& Xiang, Y. -T. (2018). Clinical characteristics and quality of life of older adults with cognitive impairment in Macao. PSYCHOGERIATRICS, 18 (3), pp.182-189. https://doi.org/10.1111/psyg.12306.

Persistent Link:

http://hdl.handle.net/11343/283576 